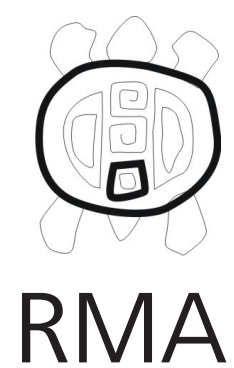

Dossier

\title{
La enseñanza de la arqueología en la Facultad de Ciencias Naturales y Museo de la Universidad Nacional de La Plata. Un análisis sobre el liderazgo académico de Alberto Rex González y Eduardo Mario Cigliano (1958-1977)
}

Germán Soprano

CONICET / Universidad Nacional de Quilmes - Facultad de Humanidades y Ciencias de la Educación de la Universidad Nacional de La Plata. E-mail: gsoprano@speedy.com.ar, gsoprano@unq.edu.ar

\begin{abstract}
Resumen
En este artículo nos centraremos en una descripción y análisis de la enseñanza de la arqueología en el ámbito de cátedras de la Facultad y Museo de Ciencias Naturales de la Universidad Nacional de La Plata entre los años 1958 y 1977. Nos ocuparemos de mostrar qué temas, métodos y autores enseñaban en las cátedras de arqueología Alberto Rex González y Eduardo Mario Cigliano, dos líderes académicos de esa institución universitaria protagonistas de un proceso de renovación en las concepciones y prácticas de la arqueología argentina, que compitieron en la formación de jóvenes arqueólogos y en la consagración de nuevas perspectivas antropológicas en esos años.
\end{abstract}

Palabras clave: enseñanza; arqueología; Alberto Rex González; Eduardo Mario Cigliano; Facultad de Ciencias Naturales y Museo de la Universidad Nacional de La Plata

The teaching of archaeology in the Facultad de Ciencias Naturales y Museo de la Universidad Nacional de La Plata. An analysis on Alberto Rex González and Eduardo Mario Cigliano's academic leadership (1958-1977)

\begin{abstract}
In this article we will focus on a description and analysis of teaching archaeology in chairs of the Facultad de Ciencias Naturales y Museo de la Universidad Nacional de La Plata between 1958 and 1977. We will show what topics, methods and authors taught Alberto Rex González and Eduardo Mario Cigliano in their archaeology chairs, two academic leaderships of this university institution involved in a process of renewal in the conceptions and practices of argentine archeology, who competed in the training of young archaeologists and the consecration of new anthropological perspectives in those years
\end{abstract}

Keywords: Teaching; archaeology; Alberto Rex González; Eduardo Mario Cigliano; Facultad de Ciencias Naturales y Museo de la Universidad Nacional de La Plata

En este artículo nos centraremos en una descripción y análisis de la enseñanza de la arqueología en el ámbito de cátedras de la Facultad y Museo de Ciencias Naturales de la Universidad Nacional de La Plata entre 1958 y 1977, enfocando temas, autores y textos comprendidos en las materias dictadas por los dos principales líderes académicos de esta especialidad antropológica en esa institución universitaria durante ese período: Alberto Rex González y Eduardo Mario Cigliano'.

Desde su creación a fines del siglo XIX, los científicos del Museo de Ciencias Naturales realizaron investigaciones antropológicas en terreno, en laboratorio y constituyeron colecciones con materiales reunidos en viajes de campaña $\mathrm{o}$ adquiridos por donaciones y compras a particulares o

\footnotetext{
${ }^{1}$ Facultad de Ciencias Naturales y Museo será citada como FCNyM y Universidad Nacional de la Plata como UNLP.
}

a otras instituciones de la Argentina y el exterior ${ }^{2}$. Con su incorporación a la Universidad Nacional de La Plata en 1906, esos científicos asumieron también tareas de enseñanza en Antropología. Desde entonces (y al menos hasta 1979 con la separación normativa de la Facultad -creada en 1949- y el Museo) la organización de la institución y de las actividades de sus miembros quedó formalmente diferenciada entre, por un lado, las funciones de investigación y exposición de Departamentos y Divisiones del Museo y, por otro lado, las de enseñanza en las Cátedras de la Escuela/Facultad ${ }^{3}$. Al comprender

\footnotetext{
${ }^{2}$ Actualmente se denomina a las Divisiones como Departamentos Científicos. Sobre la historia del Museo, su producción en investigación, creación de colecciones y exposiciones entre fines del siglo XIX y 1930, remito a trabajos de referencia de Irina Podgorny (1995), Susana García (2003) y Máximo Farro (2009).

3 Para un análisis de las relaciones entre investigación y enseñanza en ciencias naturales en la Facultad y Museo entre 1930 y 1986, puede
} 
la trayectoria de la antropología y los antropólogos en esta institución, hemos sostenido en otros trabajos que el centro de la formación académica y profesional, teórica y práctica, de los nuevos antropólogos (pero también de geólogos, botánicos, zoólogos y paleontólogos) se realizaba en actividades de laboratorio, viajes de estudio de cátedras y viajes de campaña de Divisiones ${ }^{4}$.

Por tal motivo, era necesario garantizar la provisión de recursos materiales y financieros mínimos para asegurar el desempeño cotidiano en el laboratorio y en viajes de campaña, el acceso al equipamiento y financiamiento para realizar el trabajo de campo en sitios alejados de las instituciones científicas y lugares de residencia de los antropólogos, constituir equipos de trabajo, así como asegurar una estrecha relación de intercambio con centros metropolitanos de saber científico. En este sentido, las condiciones en que se desarrollaba la antropología demandaba la adscripción de los estudiantes de grado, graduados y doctorandos en equipos de investigación radicados en las Divisiones del Museo, pues esto permitía su participación en proyectos y, en consecuencia, el acceso al laboratorio, colecciones, recursos necesarios para el trabajo de campo, becas y subsidios y publicación en revistas especializadas nacionales e internacionales. El control de esos espacios institucionales por parte de los antropólogos era un instrumento fundamental en la producción y reproducción de sus grupos académicos. En tanto que, para los jóvenes antropólogos recién graduados y/o doctorados, su incorporación a los mismos y, con ello, los compromisos intelectuales, institucionales y personales con sus líderes, constituía el único camino socialmente reconocido para iniciar una carrera profesional en el ámbito universitario y científico ${ }^{5}$.

consultarse: Soprano 2009a y 2009c

4 Hemos realizado análisis sobre la producción antropológica de la FCNyM en etnología de poblaciones indígenas y folk (Soprano 2007), antropología física (Soprano 2009b) y antropología biológica (Soprano 2009d) correspondientes a la décadas de 1930 a 1970.

5 Esta cuestión ha sido analizada por Rosana Guber (2006) para el caso de la antropología porteña, abordándola en términos de producción de linajes antropológicos. En un texto enfocado en cuestiones metodológicas (Soprano en prensa) he planteado que la configuración de liderazgos y grupos académicos puede ser investigada comprendiendo no sólo la eficacia social de lógicas y prácticas inter e intra disciplinares, rivalidades teóricas, solidaridades y disputas corporativas entre estamentos universitarios, afinidades programáticas, políticopartidarias o institucionales; sino, además, centrándose en las relaciones personalizadas y compromisos morales y afectivos. Definir esos liderazgos y grupos académicos como grupos no corporados (Wolf 1980) ayuda a elaborar una interpretación integral y compleja de las sociabilidades universitarias, evitando situar la mirada exclusivamente en la actualización de determinaciones sociales que los discursos públicos universitarios reconocen como razón de ser y existir de la universidad: la formación académica y profesional y la investigación científica de acuerdo con orientaciones teóricas y disciplinares puramente programáticas e institucionalizadas. Las dificultades metodológicas que encuentra el investigador empírico al abordar el estudio de los grupos no corporados resultan del hecho que sólo pueden ser aprehendidos reconociendo (al igual que con las facciones políticas) el dinamismo, fluidez y permanentes cambios operados en las relaciones diádicas desplegadas entre sus miembros y el líder.
Las actividades de enseñanza en las cátedras sólo adquirieron mayor relevancia a partir de la creación de la Licenciatura en Antropología en 1958, ya que en el período anterior los estudiantes pertenecían en abrumadora mayoría a las carreras de la Facultad de Humanidades y Ciencias de la Educación o Bellas Artes que las cursaban por la vigencia de un sistema de correlación de estudios. De modo que, sólo los estudiantes del Doctorado en Ciencias Naturales que aspiraban a realizar tesis en temas antropológicos cursaban esas materias en la primera mitad del siglo $X X^{6}$. Desde el comienzo de la Licenciatura se registraron entre 1961-1970 unos 27 egresados y otros 145 entre 1971-1980. Como han señalado en sus testimonios y en conversaciones informales egresados de antropología que cursaron asignaturas de arqueología en los años 1960 y 1970, las aulas o sobre todo los laboratorios del Museo donde los profesores dictaban sus clases, no sólo eran instancias de aprendizaje de temas, ámbitos para efectuar comentarios sobre textos y autores, sino también espacios en los que profesores y alumnos trababan conocimiento personal y donde se producía el reclutamiento de aquellos interesados en participar o colaborar en investigaciones ${ }^{7}$. De allí que consideremos relevante hacer una revisión de temas, textos, autores, enfoques y métodos en los programa de las cátedras.

Con la implementación progresiva del Plan de Estudios de la Licenciatura en Antropología, el dictado de las materias comenzó a operar como una instancia complementaria (aunque subsidiaria) de las actividades de investigación del Departamento de Antropología y sus tres Divisiones: Antropología, Arqueología y Etnografía. Los Jefes de esas divisiones, Eduardo Mario Cigliano, Alberto Rex González y Armando Vivante respectivamente estaban al frente de materias claves. Asimismo, otros profesores se hicieron cargo de las otras. Algunos de estos estaban insertos en cargos subalternos en las Divisiones $y$, por tanto, integraban como aliados menos poderosos o como discípulos los grupos académicos liderados por sus jefes. En tanto que otros no se inscribían como investigadores en el Museo, sumándose a la Facultad como profesores. Si los primeros recibían dedicaciones semi-exclusivas o exclusivas en cumplimiento de sus tareas de investigación y docencia; a los segundos se le asignaba una dedicación simple para cumplir tareas de enseñanza, debiendo por

\footnotetext{
${ }^{6}$ Como ha señalado Susana García (2003) desde la incorporación del Museo al ordenamiento universitario, la mayor parte de los estudiantes genuinos de esa unidad académica se inscribía sin solución de continuidad para efectuar el Doctorado en Ciencias Naturales. Sólo al promediar el siglo algunos estudiantes decidía obtener previamente el título -por entonces vigente- de Licenciado en Geología o Licenciado en Biología (Soprano 2009b).

7 De acuerdo con resultados preeliminares obtenidos por Paula Macario en la realización de una etnografía sobre la formación actual de los antropólogos en el ámbito de la FCNyM permitirán sostener que, aún en un contexto institucional en el cual la matrícula de alumnos de la Licenciatura en Antropología se ha incrementado notablemente en relación con los años sesenta y setenta, todavía hoy las cátedras constituyen instancias de reclutamiento e incorporación de los estudiantes a los equipos de investigación en arqueología.
} 


\begin{tabular}{|c|c|c|}
\hline Materia & Año & Profesor a cargo \\
\hline Prehistoria General $^{9}$ & 1966 & Eduardo Mario Cigliano \\
\hline Prehistoria General & 1967 & Delfor H. Chiappe \\
\hline Prehistoria General & 1970 & Alberto Rex González \\
\hline Prehistoria General $^{10}$ & $1971 / 1980$ & Pedro Krapovickas \\
\hline Prehistoria del Viejo Mundo & $1966 / 1967$ & Eduardo Mario Cigliano \\
\hline Prehistoria del Viejo Mundo & $1968 / 1980$ & Antonio Austral \\
\hline Arqueología Americana (culturas pre-cerámicas) & 1966 & Alberto Rex González \\
\hline Arqueología Americana (culturas pre-cerámicas) & $1967 / 1980$ & Augusto Cardich \\
\hline Arqueología Americana (culturas agro-alfareras) & $1966 / 1968$ & Alberto Rex González \\
\hline Arqueología Americana (culturas agro-alfareras) & $1969 / 1977$ & Ana María Lorandi \\
\hline Arqueología Americana (culturas agro-alfareras) & $1978 / 1979$ & Carlota Sempé de Gómez Llanes \\
\hline Arqueología Americana (culturas agro-alfareras) & 1980 & Ana María Lorandi \\
\hline Arqueología Argentina & 1967 & Eduardo Mario Cigliano \\
\hline Arqueología Argentina & 1969/1976 & Alberto Rex González \\
\hline Arqueología Argentina & $1978 / 1980$ & Bernardo Dougherty \\
\hline Técnica de la Investigación Arqueológica & 1966/1976 & Eduardo Mario Cigliano ${ }^{11}$ \\
\hline Técnica de la Investigación Arqueológica & $1979 / 1980$ & Augusto Cardich \\
\hline Sistemas de subsistencia pre-europeos del nuevo mundo ${ }^{12}$ & $1977 / 1980$ & Rodolfo Raffino \\
\hline
\end{tabular}

Tabla 1. Materias de arqueología y sus profesores entre 1966 y 1980 (de acuerdo a los dos planes de Licenciatura vigentes en el período.

ello lograr el financiamiento de sus proyectos a través de otras instituciones científicas, educativas, estatales o recursos personales.

\section{Planes de Estudio Licenciatura en Antropología Vigentes entre 1958 y 1980.}

En el período abordado por este artículo estuvieron vigentes tres planes de estudio que apostaban a una formación antropológica bio-socio-cultural u holística e inscripta en el campo de las ciencias naturales ${ }^{8}$. El primero

\footnotetext{
8 Es notable el contraste, en este sentido, respecto de la inscripción institucional e interlocutores académicos con los que se relacionaban los antropólogos de la UBA en el ámbito de la Facultad de Filosofía y Letras. Si en La Plata el diálogo cotidiano era establecido en el nivel universitario con geólogos, botánicos, zoólogos y paleontólogos; en Buenos Aires lo era con historiadores, geógrafos, filósofos, pedagogos y especialistas en lenguas antiguas y modernas. Para un análisis del
}

fue el Plan 1958/ 1965 que comprendió las siguientes materias: $1^{\circ}$ año: Zoología General, Fundamentos de Botánica, Geología General, Fundamentos de Antropología, Introducción a la Química y Química Inorgánica.

$2^{\circ}$ año: Prehistoria del Viejo Mundo, Arqueología Americana I, Etnología General, Geología y Paleontología del Cuaternario, Anatomía Humana.

$3^{\circ}$ año: Arqueología Americana II, Etnografía Americana, Arqueología Argentina, Antropología Biológica I, Complementos de Matemática.

$4^{\circ}$ año: Antropología Biológica II, Cálculo Estadístico y Biometría, Evolución, Técnica de la Investigación Arqueológica.

$5^{\circ}$ año: Raciología y tres materias optativas.

contexto de emergencia de la Licenciatura porteña: Visacovsky, Guber y Gurevich (1997). 
Este plan exigía una tesis para la obtención del título de Licenciado en Antropología. Para obtener el titulo de Doctor en Ciencias Naturales los estudiantes debían tomar dos cursos optativos adicionales y realizar una tesis de doctorado. El siguiente plan rigió entre 1966/1968. Este produjo una modificación importante al reconocer la diferenciación en tres orientaciones: Arqueología, Antropología Biológica y Antropología Sociocultural. En ese nuevo marco algunas materias mudaron de nombre: Arqueología Americana I pasó a denominarse Arqueología Americana (culturas pre-cerámicas) y Arqueología Americana II como Arqueología Americana (culturas agro-alfareras). Finalmente, entre 1969 y 1980 estuvo vigente un nuevo plan que mantuvo los lineamientos generales del anterior, aunque desde 1973 se suprimió la exigencia de realizar una tesis de licenciatura y, desde 1977, se cerró la inscripción en la orientación Sociocultural. A partir de 1958 las materias de la Licenciatura fueron implementándose progresivamente mediante la incorporación de profesores formados y/o procedentes de la Universidad de Buenos Aires y del Litoral. Desde 1966 hasta la modificación del plan de estudios en 1980 también se sumaron antropólogos graduados en la FCNyM de la UNLP. Los profesores a cargo de materias de arqueología en el período fueron los que se nombran en la Tabla 1

A continuación referiremos a las trayectorias académicas e institucionales universitarias de González y Cigliano, deteniéndonos luego en una revisión y análisis de los programas de dos materias dictadas por ellos: "Arqueología Argentina" y "Técnica de la Investigación Arqueológica", respectivamente.

\section{Los liderazgos académicos de Alberto Rex González y Eduardo Mario Cigliano}

Alberto Rex González (nacido en 1918) se había graduado como Doctor en Medicina por la Universidad Nacional de Córdoba. Ingresó al Museo de La Plata a principios de 1949 (tras realizar estudios de doctorado en la Universidad de Columbia entre junio de 1946 y fines de 1948) desempeñando funciones como arqueólogo en reemplazo de Fernando Márquez Miranda, docente e investigador

\footnotetext{
${ }^{9}$ Esta materia no aparece consignada en los registros que disponemos de los planes de estudios vigentes entre 1958 y 1980. Su ausencia puede deberse a que fuese dictada por el sistema de correlación de estudios para otras carreras de la FCNyM u otras (por ejemplo Humanidades y Ciencias de la Educación), que fuese un error en las fuentes consultadas, o bien se tratarse de una asignatura optativa de la Licenciatura y Doctorado.

10 Según consta en el expediente 1346 de 1971, ese año Antonio Austral dictó los temas 1 a 4 de "Prehistoria General" y Krapovickas (contratado el $1^{\circ}$ de noviembre de 1971) los temas 5 a 7

11 Desde 1973 el Jefe de Trabajos Prácticos de esta cátedra era Rodolfo Raffino.

12 En 1977 se presentó el proyecto de creación de esta materia para Antropología.
}

exonerado en $1946^{13}$. Tuvo una trayectoria discontinua en este Museo y Facultad. A fines de 1955 al asumir Márquez Miranda como decano y Jefe de las Divisiones de Antropología y de Arqueología y Etnografía, González fue confirmado como profesor interino de la cátedra de Antropología y como Jefe Asesor de Investigaciones de Arqueología y Etnografía. Pero los conflictos personales y científicos existentes entre ambos terminarían con el desplazamiento de González, quien se alejó de la institución platense en $1957^{14}$. Su trayectoria profesional, sin embargo, no quedó trunca, pues desde 1954 reemplazó a Antonio Serrano como Director del Instituto de Antropología de la Facultad de Filosofía y Letras de la Universidad Nacional del Litoral (Rosario), ejerciendo esa función hasta 1957. Aunque la intervención universitaria de 1955 impuso cesantías e impulsó públicamente pautas discriminatorias en la inscripción a concursos de aquellos docentes e investigadores activos durante el período peronista, González fue ratificado en sus cargos. Pero en 1957 radicó su actividad como investigador en la Universidad Nacional de Córdoba, donde fue convocado una vez más por Serrano para ocupar el cargo de director del Instituto de Antropología que éste dejaba vacante. Según González, su alejamiento de Rosario se debió a un conflicto institucional, que no melló la fructífera relación que continuó manteniendo con docentes y estudiantes rosarinos que compartieron con él proyectos de investigación. Finalmente, su reincorporación full time en La Plata se produjo en 1962, tras el fallecimiento de Márquez Miranda en 1961 y con la resolución en su favor del litigio que tenía con éste último por el concurso a un cargo al que ambos aspiraron en 1959. Ya de regreso a sus actividades en La Plata, desde 1963 estuvo a cargo de la División de Arqueología del Museo hasta 1976, cuando fue cesanteado por la intervención universitaria del "Proceso de Reorganización Nacional" (1976-1983). En este último período pasó a concentrar su actividad

\footnotetext{
13 Sobre la trayectoria de González en Estados Unidos, ver el artículo de Gastón Gil en este dossier. Por nuestra parte, efectuamos una revisión de la producción académica de González, su circulación institucional entre las Universidades Nacionales de La Plata, el Litoral y Córdoba y las redes de discípulos que fue conformó, en Bonnín y Soprano 2010.

14 Las diferencias profesionales -en la perspectiva de González- quedaron explicitadas en su artículo: "Observaciones al trabajo de F. M. Miranda y E. M. Cigliano. 'Ensayo de una clasificación tipológico-cronológica de la cerámica santamariana" de 1959. En cuanto a la dimensión personal del conflicto, de acuerdo con un relato ofrecido por González en una entrevista efectuada por José A. Pérez Gollán (1998), las causas que motivaron su "cesantía" no fueron suficientemente explicitadas y no estaba relacionadas con una "supuesta adscripción política" al gobierno peronista depuesto; por el contrario, tenían que ver con diferencias que mantenía con Márquez Miranda sobre "un tema científico". Mientras residió en Rosario y Córdoba, González se presentó al concurso por el cargo que Márquez Miranda ocupaba en La Plata. En su testimonio dice: "Yo me presenté y él también. Ese concurso se resolvió tres veces a favor mío y tres veces volvió a foja cero... el Profesor Márquez Miranda murió y entonces gané la cátedra en forma definitiva". Una revisión del expediente del concurso FCN $5849 / 1959$ y agregados, confirma los testimonios posteriores ofrecidos por González. Interpretaciones de las dimensiones personales y profesionales fueron brindadas ulteriormente por González en dos testimonios (González 2000 y Bianciotti 2005).
} 
académica en el CONICET y la Universidad del Salvador. Con la implementación del plan de la Licenciatura del año 1966, González comenzó a dictar en la FCNyM la materia "Arqueología Americana (culturas pre-cerámicas)", también llamada "Arqueología Americana I" del Plan 1958. Entre 1966 y 1968 enseñó en "Arqueología Americana (culturas agro-alfareras)" o "Arqueología Americana II" del "plan viejo". Y, circunstancialmente, estuvo a cargo de "Prehistoria General" en 1967. Pero la materia en que se erigió como referente permanente durante esos años fue "Arqueología Argentina", que enseñó en forma continua entre 1969 y 1976, cuando fue reemplazado por Bernardo Dougherty, a quien había dirigido en su tesis de doctorado.

Eduardo Mario Cigliano (1926-1977) se había formado como Licenciado en Ciencias Biológicas y, luego, como Doctor por la FCNyM/UNLP en septiembre de 1955. Su tesis contó con la dirección de González, pero Cigliano mantenía estrechos vínculos intelectuales y personales contraídos con el entonces exonerado Fernando Márquez Miranda. Su ascendente trayectoria institucional estuvo ligada desde 1955 al regreso de este último como decano interventor de la Facultad. Cigliano reemplazó al desplazado Milcíades Alejo Vignati como Jefe de la División de Antropología durante el decanato de Márquez Miranda quien, a su vez, retuvo para sí la Jefatura de la División Arqueología y Etnografía hasta su muerte ${ }^{15}$. Casi simultáneamente Cigliano se hizo cargo de la Dirección del Instituto de Antropología en Rosario en 1958, tras el alejamiento de González. En la Universidad Nacional del Litoral consolidó un equipo de colaboradores y estudiantes que lo acompañó en sus investigaciones en el Valle de Santa María en la provincia de Catamarca. Al igual que Márquez Miranda y González, sus investigaciones

\footnotetext{
15 Hemos abordado la trayectoria de Vignati y la génesis, desarrollo y disolución de su grupo académico en: Soprano 2009b.
}

\begin{tabular}{llll}
\hline Año/ N & Desis & Autor & Título \\
\hline & & & \\
$1955 / 230$ & Eduardo Mario Cigliano & Alberto Rex González & $\begin{array}{l}\text { Arqueología de la zona de Famabalasto. } \\
\text { Provincia de Catamarca. República Argentina }\end{array}$
\end{tabular}

1962 / $252 \quad$ Horacio D. Chiappe Alberto Rex González

1970 / $282 \quad$ Héctor Blas Lahitte Rodolfo Agoglia

1970 / $285 \quad$ Rodolfo A. Raffino

Eduardo M. Cigliano

Estudio Arqueológico de la Colección Methfessel del Museo de La Plata

Integración y metodología de las ciencias humanas ${ }^{20}$

Estudio sobre los sitos de cultivo en la Quebrada del Toro y borde puneño meridional de la provincia de Salta

Estudio sobre los textiles del yacimiento arqueológico de Santa Rosa de Tastil (Provincia de Salta)

Diana Susana Rolandi de Perrot

Eduardo M. Cigliano

Nuevos aportes para el conocimiento del complejo arqueológico San Francisco (sector septentrional de la región de las selvas occidentales, subárea del noroeste argentino)

Contribución a la arqueología del valle de Abaucán, Departamento de Tinogasta, provincia de Catamarca

Arqueología y ambiente natural de los Valles del

1977 / 353 Humberto Lagiglia Eduardo M. Cigliano Atuel y Diamante, San Rafael 
en terreno y área de especialización fue el Noroeste Argentino. Desde 1966 dictó varias materias hasta que se completó la planta docente de la FCNyM: "Prehistoria General" en 1966, "Prehistoria del Viejo Mundo" en 19661967 y "Arqueología Argentina" en 1967¹6. Pero estuvo al frente en forma permanente desde 1966 hasta 1976 en "Técnica de la investigación arqueológica"17.

En 1964 se sumó al staff académico de la FCNyM el ingeniero agrónomo (formado en la UNLP) Augusto Cardich, oriundo del Perú, quien fue designado como profesor adjunto contratado. Contaba con trayectoria académica previa afirmada en los estudios que efectuó sobre los yacimientos de Lauricocha (Perú) cuyos avances publicó en 1958 en la revista porteña Acta Prehistórica y otros resultados en 1960 en Investigaciones Prehistóricas en los Andes Peruanos de Lima. Desde 1967 fue titular de la cátedra "Arqueología Americana (culturas precerámicas)". A medida que entró en vigencia plena el Plan de estudios de 1966 se sumaron otros arqueólogos. Ana María Lorandi y Pedro Krapovickas provenían de la Universidad Nacional del Litoral donde, recordemos, habían ejercido docencia e investigación González y Cigliano $^{18}$. En esta última casa de estudios la intervención universitaria de 1966 produjo cesantías y redundó en renuncias de docentes en solidaridad con los exonerados. También se incorporó Antonio Austral procedente de UBA. Desde 1969 Lorandi dictó "Arqueología Americana (culturas agro-alfareras)", Austral "Prehistoria del Viejo Mundo" desde 1968 y Krapovicas "Prehistoria General" desde $1971^{19}$. Ninguno de estros tres antropólogos se desempeñó como investigador en las Divisiones del Departamento de Antropología del Museo, razón por la cual su condición académica en la institución era considerada como "extranjera" por aquellos que se reconocían como "locales" en la medida en que ocupaban cargos como investigadores y docentes. La atribución de ese rótulo (negativamente connotado) de extranjería se sostenía aún cuando ejercieran como docentes de la Licenciatura y en torno suyo se integraran como ayudantes de cátedra algunos estudiantes y jóvenes graduados de la casa. En ese sentido no disponer de cargos de investigación propios y para sus discípulos en las Divisiones del Museo constituía no sólo una limitación en la disponibilidad de recursos materiales y humanos, sino un demérito en los estándares de prestigio institucional de los actores sociales.

\footnotetext{
16 Como veremos más abajo "Arqueología Argentina" sería dictada desde 1969 por González.

17 Además de González y Cigliano, la investigación y/o enseñanza en arqueología se completó en 1950 con la contratación de Oswald Menghin como investigador y profesor interino de "Prehistoria" en 1957. Menghin permaneció en La Plata hasta 1960 cuando obtuvo una dedicación exclusiva en la UBA. Ese año fue nombrado "profesor honorario" de la FCNyM.

18 Krapovickas había sucedido a Cigliano en la dirección del Instituto de Antropología en los años 1963-1966.

19 "Prehistoria General" había sido dictada en forma intermitente por Cigliano (1968), González (1969) y Chiappe (1970).
}

Si efectuamos una revisión de las tesis de doctorado orientadas en temas de arqueología defendidas hasta 1977, identificamos a González y Cigliano como actores institucionalmente relevantes (Tabla 2).

De estas siete tesis de doctorado orientadas en arqueología, cuatro tuvieron dirección de González (Cigliano, Chiappe, Dougherty, Sempé de Gómez Llanes) y tres de Cigliano (Raffino, Rolandi de Perrot, Lagiglia). Puede constatarse también que aquellos arqueólogos que sólo dictaban clases no tuvieron tesistas de doctorado en la FCNyM durante el período ${ }^{21}$. Ahora bien, la sola identificación de la dirección de tesis no permite explicar la producción de una relación discipular ni la aceptación por parte del tesista del liderazgo de su director o la inclusión del primero en su grupo. Veamos esta cuestión con más detalle. Primero: González dirigió la tesis de Chiappe, pero (tal como analizamos en Soprano 2007) éste hizo su carrera académica bajo el liderazgo del etnólogo Armando Vivante, con quien compartió sus orientaciones teóricas histórico-culturales y abordó el estudio de poblaciones aborígenes actuales. En segundo lugar, de acuerdo con testimonios de graduados de la Licenciatura que cursaron en la década del setenta, Héctor Blas Lahitte había iniciado su tesis con dirección de González, pero entró en conflicto con él y fue el filósofo Rodolfo Agoglia quien terminó ejerciendo sólo formalmente la dirección. En tercer lugar, los tesistas de doctorado de Cigliano y González no necesariamente desarrollaron sus carreras académicas en la FCNyM ${ }^{22}$ y, además, sus grupos académicos estaban integrados por miembros de otras instituciones universitarias ${ }^{23}$. Por último, González dirigió la tesis de Cigliano, pero se trató de una dirección formal, dado que este último se reconocía discípulo de Márquez Miranda quien, por entonces, estaba exonerado de todo cargo de las universidades nacionales. Las concepciones teóricas y la metodología de trabajo de campo de Márquez Miranda y González eran diferentes: histórico-culturales uno y evolucionista el otro; centrado en la observación en terreno de las construcciones (preferentemente en superficie) y excavaciones producidas en forma a-sistemática en busca de objetos en uno, y un activo

\footnotetext{
20 Esta tesis no se encuentra en la Biblioteca de la Facultad. Sobre su contenido nos orientamos por un artículo de Lahitte -publicado 1970 en la serie de monografías del Museo Etnográfico Municipal Dámaso Arce- que está ligado su tema de la tesis: Arte y Arqueología: un análisis documental sobre piezas de la cultura santamariana.

21 Y aún después de ese período sólo Lorandi dirigió dos -defendidas en 1996 y 1997 cuando hacía ya diez años que había dejado la docencia en esta unidad académica y concentró sus actividades en la UBA. 22 Lagiglia se radicó en Mendoza.

23 De acuerdo con Mirta Bonnín: los arqueólogos "cordobeses" discípulos de González -Osvaldo Heredia, José Antonio Pérez y Héctor Núñez Regueiro- lo siguieron hasta La Plata, aún cuando no hicieron allí sus posgrados, ni consiguieron insertarse en esa unidad académica como investigadores y docentes. En Rosario Cigliano dirigió un proyecto sobre el Valle de Santa María con participación de María Teresa Carrara, Ana María Lorandi, Susana Renard, Myriam Tarragó, Graciela de Gásperi, Susana Petruzzi, María Luisa Arocena, Susana Beretervide y Blanca Carnevali (Cigliano 1960 y 1962).
} 
difusor y ejecutante práctico del método estratigráfico y de la datación por carbono 14 en el otro. Esas diferencias teórico-metodológicas apuntadas arriba entre Márquez Miranda y González tenían, a su vez, implicancias en los conocimientos sustantivos producidos sobre la arqueología de la región del noroeste argentino. En primer lugar, Márquez Miranda construyó una interpretación de aquellas poblaciones reconociéndoles una homogeneidad socio-cultural que le permitía caracterizarlos como "diaguitas", término con que fueron nominadas las poblaciones de los Valles Calchaquíes en tiempos de la conquista española. En tanto que González se esforzó por identificar una pluralidad de culturas arqueológicas locales en una dinámica cultural regional más amplia que comprendía al noroeste argentino inscripto con sus áreas aledañas, señalando que era un craso error atribuir homogeneidad a esas culturas y presuponer la existencia necesaria de cualquier continuidad cultural entre las poblaciones prehispánicas y las que hallaron los conquistadores españoles en el siglo XVI. En ese sentido, el recurso técnico de las cuadrículas y la estratigrafía en las excavaciones, la datación de los objetos obtenidos en los sitios por el método de carbono 14, el uso crítico de las crónicas españolas y la aplicación de un enfoque teórico evolucionista, permitieron a González despegarse de las interpretaciones antropológicas dominantes sobre el noroeste argentino.

\section{La enseñanza de la arqueología en las cátedras de González y Cigliano.}

Decíamos que desde 1958 los conocimientos antropológicos no sólo se enseñaban en laboratorios o viajes de campaña. Las cátedras también fueron espacios de circulación y enseñanza de conocimientos desde la creación de la Licenciatura, así como espacios de reclutamiento de los futuros arqueólogos. Presentaremos a continuación contenidos, métodos, autores y textos de las materias enseñadas por González y Cigliano. Nos ocuparemos en forma prioritaria de las dos materias que dictaron durante más tiempo y en torno de las cuales se erigieron como referentes en la institución.

Los temas, autores y textos de los programas de "Arqueología Argentina" dictada por González fueron estables entre 1969-1975. La parte de contenidos generales hacía foco en: 1) Historia de las investigaciones arqueológicas en la Argentina: etapas; métodos y técnicas; análisis crítico. 2) Áreas culturales sudamericanas; áreas culturales del territorio argentino; superárea andina y sus divisiones; área andina meridional. 3) Etnohistoria: crónicas y arqueología; principales cronistas; uso crítico de crónicas en la arqueología argentina. 4) Patrones de poblamiento; geografía y ecología; estudios estructurales. En tanto que la parte específica en: 1) Etnohistoria y Arqueología del Área del Noroeste Argentino y relaciones con áreas vecinas (Chile y Bolivia). Región Valliserrana y Quebrada de Humahuaca del Noroeste; Región Chaco-
Santiagüeña y Sierras Subandinas; Puna Argentina; Sierras Centrales; Conceptos: orígenes y dinámica cultural; adaptaciones culturales locales (con referencia al área noroeste). 2) Área de Chaco y Misiones; Área Litoral; 3) Región Pampeana y Litoral Atlántico; 4) Patagonia y Tierra del Fuego. En relación con los métodos y técnicas enseñados, se destacaba el reconocimiento de materiales líticos y cerámicos característicos de cada fase cultural de las áreas/sub-áreas y la elaboración de mapas de áreas y diseños de elementos que integran los contextos culturales.

En la bibliografía ocupaban un lugar destacado arqueólogos argentinos y extranjeros cuyas investigaciones definieron orientaciones básicas para los estudios arqueológicos del noroeste-que concitaba el mayor interés de González en el programa- tales como: Eric Boman, Juan B. Ambrosetti, Roberto Leviller, P.A. Larrouy, Romualdo Ardisone, Eduardo Casanova, Salvador Debenedetti, Alberto Salas, Salvador Canals Frau, Fernando Márquez Miranda, el geólogo Joaquín Frenguelli, Stig Ryden, José Alcina Franch, Gordon Willey y Wendell Bennett ${ }^{24}$. También incluía antropólogos argentinos contemporáneos como Guillermo Madrazo, Eduardo Mario Cigliano y jóvenes arqueólogos que trabajaban con este último: Rodolfo Raffino y Horacio Calandra ${ }^{25}$. Para la región de Cuyo contaba con trabajos

24 Gustavo Politis (1995) destaca la importancia de los "peruanistas" norteamericanos Bennett y Willey en la promoción de una nueva conceptualización de la arqueología correspondiente a los Andes Centrales y áreas vecinas, particularmente, desde fines de la década de 1940, empleando los términos "función y contextos" como pivotes para generar renovadas interpretaciones históricas y antropológicas en la región. Ambos autores norteamericanos influyeron en los cursos dictados por González, pero luego veremos que también en los de Cigliano. Asimismo, Politis también llama la atención que no debe desconsiderarse en los estudios arqueológicos de la época de la impronta de la Misión Científica Española en el Perú, bajo dirección de José Alcina Franch, quien estaba principalmente interesado en probar su modelo de las interconexiones oceánicas en base a difusiones culturales de larga distancia.

25 J.B. Ambrosetti, Notas de arqueología calchaquí; Exploraciones arqueológicas de la Pampa Grande; Apuntes sobre arqueología de la Puna de Atacama; Exploraciones arqueológicas en la ciudad prehistórica de la Paya; W. Bennett, The Andean Highlands (en: Handbook of South American Indians); Northwest Argentina Archaeology; G. Willey, The Culture of La Candelaria (en: Handbook of South American Indians); An Introduction to American Archaeology, II, South America; E. Boman, Enterratorio Prehistórico en Arroyo del Medio; Antiquités de la région Andine de la République Argentine et du Désert d'Atacama; E. Bleiler, The Archaeology of Northwestern Argentina; E. Casanova, The culture of the Puna and the Quebrada de Humahuaca (en: Handbook of South American Indians); E.M. Cigliano, Arqueología de la Zona de Famabalasto (Departamento de Santa María, Prov. Catamarca); E.M. Cigliano, R.A. Raffino y H.A. Calandra, Nuevos aportes para el conocimiento de las entidades alfareras más tempranas del Noroeste Argentino; E.M. Cigliano y R.A. Raffino, Tastil: un modelo cultural de adaptación, funcionamiento y desarrollo de una sociedad urbana prehistórica; S. Debenedetti, Exploración arqueológica en los cementerios prehistóricos de la Isla de Tilcara (Quebrada de Humahuaca, Prov. De Jujuy); J. Frenguelli, Ocupación Humana en el Valle de Santa María; R. Ardissone, La instalación indígena en el Valle Calchaquí; A.R. González, Contextos culturales y cronología relativa en el área central del Noroeste Argentino; Dos fechas de la cronología arqueológica argentina obtenidas por el método de radiocarbón; La Cultura Condorhuasi del Noroeste Argentino. Apuntes preelimi- 
de Debenedetti, Canals Frau, Mariano Gambier y Pablo Sacchero ${ }^{26}$. Sobre Sierras Centrales se apoyaba en contribuciones de Antonio Serrano, G.A. Gardner y experiencias propias ${ }^{27}$. Para el Litoral recurría a Luís María Torres, Serrano, Samuel Lothrop y Oswald Menghin ${ }^{28}$. Para Pampa y Patagonia a Marcelo Bórmida, Menghin y Antonio Austral29. Destaquemos, además, que revestían importancia trabajos de González y sus discípulos de la Universidad Nacional de Córdoba, Osvaldo Heredia y José Pérez ${ }^{30}$, e incluía textos de referencia general de Alcina Franch, Manual de Arqueología Americana, Canals Frau, Las poblaciones indígenas de la Argentina y Palavecino, Áreas culturales del territorio argentino ${ }^{31}$.

Desde 1972 la materia incorporó en los contenidos generales consideraciones sobre la Arqueología en las Ciencias del Hombre, tendencias en la Arqueología Americana y Argentina, con una referencia a los aportes de la "Nueva Arqueología" que -sin embargo- no

nares para su estudio; La Cultura de la Aguada del Noroeste Argentino; Cultural Development in Northwest Argentina; Las tradiciones alfareras del período temprano del N.O. Argentino y sus relaciones con las áreas aledañas; G. Howard y G. Willey, Lowland Argentine Archaeology; P-A. Larrouy, Los indios del Valle de Catamarca. Estudio Histórico; R. Levillier, Nueva crónica de la conquista del Tucumán; G. Madrazo, Reapertura de las investigaciones en Alfarcito, Prov. de Jujuy; F. Márquez Miranda, La arqueología de la Puna Argentina a través de nuevos hallazgos; Los diaguitas; $\mathrm{H}$. Reichlen, Recherches archéologiques dans la provincia de Santiago del Estero; S. Ryden, Archaeological Researches in the Department of Candelaria; A. Serrano, Investigaciones arqueológicas en el Valle del Río San Francisco; A. Salas, Excavaciones arqueológicas en Ciénega Grande.

26 S. Debenedetti, Investigaciones arqueológicas en los valles preandinos de la provincia de San Juan; L'Ancienne civilisation des Barreales; M. Gambier y P. Sachero, Secuencias culturales y cronología para el S.O. de la Provincia de San Juan.

27 A. Serrano, Los comechingones; G.A. Gardner, Rock-paintings of North-West Córdoba.

28 S. Lothrop, Indians of the Paraná Delta. O. Menghin, El Altoparanaense y El doblamiento prehistórico de Misiones. A. Serrano, Exploraciones arqueológicas en el Río Uruguay; Arqueología del Arroyo de las Mulas en el Noroeste de Entre Ríos; Líneas fundamentales de la arqueología del Litoral (una tentativa de periodización); L.M. Torres, Arqueología de la Cuenca del Paraná; Los primitivos habitantes del delta del Paraná; F. de Aparicio, Los paraderos de la margen derecha del Río Malabrigo.

29 O. Menghin, Fundamentos cronológicos de la Prehistoria de la Patagonia; A. Austral, Investigaciones prehistóricas en el curso inferior del Río Sauce Grande; El yacimiento arqueológico Vallejo en el N.O. de la Provincia de La Pampa; J.B. Bird, Antiquity and Migrations of the Early Inhabitants of Patagonia; The Archaeology of Patagonia (en: Handbook of South American Indians); M. Bórmida, Arqueología de la costa norpatagónica; Problegómenos para una arqueología de la Pampa Bonaerense.

30 A.R. González y J.A. Pérez, El área meridional; Argentina Indígena. Vísperas de la Conquista; O. Heredia, Excavaciones arqueológicas en La Candelaria; J.A. Pérez, Subáreas de Humahuaca.

31 Una porción de la bibliografía correspondiente al programa de 1975 presentan anotaciones manuales con la indicación "si", que interpretamos destacan autores y textos que debían ser trabajados por Ios estudiantes: Ambrosetti, Debenedetti, Torres, Canals Frau, Serrano, Salas, Márquez Miranda, Cigliano, Raffino, Calandra, Menghin, Bórmida, González, Heredia y Madrazo; Boman, Alcina Franch, Howard, Gardner, Ryden y Willey. Pero no pudimos confirmar si las anotaciones eran de González o fueron hechas ulteriormente por otros. guarda correspondencia con citas de textos ni autores específicos expresivos de esta corriente arqueológica metropolitana ${ }^{32}$. Los programas de trabajos prácticos preveían la aprobación del curso mediante la elaboración de una monografía. El reconocimiento de materiales líticos y cerámicos característicos de las fases culturales de cada área o sub-área se realizaba en el ámbito de los laboratorios y salas del Museo, así como en "visitas a los principales centros arqueológicos del N.O. o Litoral argentino, de acuerdo con los medios que se cuenten para el traslado". El programa de 1971 incorporó la lectura y comentarios de crónicas históricas para sumar el enfoque etno-histórico como vía de conocimiento de los "pueblos históricos". También manifestaba que se haría un tratamiento de desigual profundidad en algunos temas, atendiendo a la orientación de la Licenciatura escogida por los alumnos: más intensidad en el caso de arqueología y menos en antropología biológica y sociocultural.

El concepto de áreas culturales operaba a modo de organizador teórico y descriptivo de los temas ${ }^{33}$. Si comparamos las clasificaciones expresadas en los programas con Argentina Indígena, vísperas de la conquista, un libro publicado por González y José Antonio Pérez en 1972 en una colección sobre Historia Argentina dirigida por Tulio Halperín Donghi, verificaremos similitudes, aunque no taxativas coincidencias, ya que en los programas Chaco-Misiones eran presentados en forma conjunta; en tanto en el libro se identificaba al Chaco como un área y Litoral-Mesopotamia como otra ${ }^{34}$.

32 A pesar de esta ausencia a referencias sustantivas de la "nueva arqueología" anglosajona en el programa, señalamos que Máximo Farro, Irina Podgorny y María Tobías (1999) sostienen que las arqueología enseñada e investigada por González en la FCNyM hizo que sus discípulos fueran particularmente receptivos a las propuestas innovadoras de esta nueva corriente cuyas ideas. Por su parte, Susana Luco (2010) observa que las influencias de la "nueva arqueología" tendieron a desplegarse en el ámbito universitario porteño circulando de un modo bastante informal y personalizado durante la década de 1970 a través de actores académicos (jóvenes profesores como Carlos Aschero y estudiantes Luis Borrero) no consagrados y a contracorriente de las tendencias histórico-culturales dominantes en esa casa de estudios.

33 En el programa de "Arqueología Argentina" la sola mención a áreas culturales no constituye necesariamente una evidencia en favor de la adopción de un singular enfoque teórico neo-evolucionista por parte de González, ya que constatamos el programa de "Prehistoria y Arqueología Americana" de la Facultad de Filosofía y Letras de la UBA dictado en 1963 por un arqueólogo de orientación histórico-cultural, Ciro René Lafon, también se sirve de similares regiones arqueológicas: el Noroeste Argentino, las zonas marginales del Noroeste, las Sierras Centrales, el Litoral y Pampa y Patagonia. Asimismo, el concepto de áreas culturales había sido utilizado previamente por Enrique Palavecino (1948) -un antropólogo también de orientación histórico-cultural mencionado en el programa de González- para establecer regiones etnográficas del territorio argentino que, según su parecer, en líneas generales coincidían con las arqueológicas: pescadores de la costa del pacífico, cazadores de guanaco, chaquenses, amazónicos, amazónicos del litoral, culturas andinas.

34 De hecho son amplias las coincidencias en las menciones a textos y autores existentes entre los programas de "Arqueología Argentina" y la bibliografía citada en el libro. No obstante, es llamativa la ausencia en el programa de textos de tres autores que, sí, son de referencia 
La definición de áreas culturales y ecología provista en ese libro es una referencia del modo cómo eran comprendidos esos conceptos por González: "Para entender las culturas indígenas es necesario conocer su distribución geográfica y su relación con el medio. Este aspecto de adaptación, dependencia e influencia del medio físico sobre la cultura se manifestó con más fuerza en las de menor desarrollo; por lo tanto, es fundamental para desentrañar esta relación dinámica". De acuerdo con esta interpretación, el "gran centro irradiador de civilización" o Centro Nuclear Andino localizado en el actual territorio de Perú ejerció una enorme influencia cultural sobre la llamada Área Andina Meridional en lo que hoy es el noroeste argentino, el sur de Bolivia y norte de Chile. El "medio geográfico" obraría como factor determinante en el "desarrollo cultural". Así, cada área podía ser dividida en sub-áreas "de acuerdo con sus caracteres botánicos, climáticos y fisiográficos". Asumía que esos rasgos de una "región geográfica" influían notablemente en la "personalidad cultural" y la "adaptación ecológica".

En el caso del área Litoral-Mesopotamia, por ejemplo, se reflejaba en el perfil de las sub-áreas o los "tipos de ecología cultural" que la componían: "una adaptación a las florestas tropicales y los grandes ríos; otra de nómades cazadores recolectores ocupantes del interior y, por último, algunas formas intermedias entre ambas" (González y Pérez 1972:27-29). González pensaba que, así como el Centro Nuclear Andino irradiaba su influencia cultural hacia el Área Andina Meridional, esta última producía un efecto similar sobre las poblaciones de "menor desarrollo cultural" (como serían los "cazadores recolectores inferiores" frente a los que poseen una "economía hortícola" y, a su vez, estos últimos por contraste con los que tienen "agricultura") o bien sobre las "culturas marginales" de las áreas de Sierras Centrales y Pampa-Patagonia. Cada una de esas "áreas culturales" y sus "fases culturales específicas" (en el tiempo) podían reconocerse por los materiales líticos y cerámicos "típicos", "característicos", "diagnóstico" o "comunes", así como por los diseños y pinturas, hallazgos vegetales, de restos humanos y animales y por las construcciones de los sitios arqueológicos, los cuales evidenciaban patrones de asentamiento, organización social, desarrollo tecnológico y artístico, economía y constitución política. Trataba así de diferenciarse de los análisis "especulativos" y de las técnicas de "recolección" asistemáticas en el terreno efectuadas por arqueólogos precedentes. Para González esos materiales adquirían sentido sólo "en contexto"35.

teórica y/o sustantiva en el libro: John Murra, Ángel Palerm y Eric Wolf.

35 En un testimonio posterior refiriéndose a su ayudante de División, Domingo García, González define en forma contundente y sencilla este enfoque y método de análisis: "... una vez, cuando yo buscaba armar los contextos de la culturas del noroeste, me dijo: 'Yo se lo que usted busca, usted busca las cosas que van juntas'. Así describió en dos palabras, de una manera muy gráfica, la organización de los contextos que para entonces carecían totalmente de interés, ni habían sido ensayados, salvo en parte por el libro de Bennett pero no como
El método de excavación estratigráfico y el recurso del carbono 14 permitían la datación de los materiales y, en correspondencia, de los sitios y culturas asociados. En este sentido, el enfoque de González -que a menudo ha sido rotulado como "evolucionista" por él mismo o por sus analistas- se revela más bien como expresivo de una combinación de lógicas interpretativas evolucionistas y difusionistas sobre la "dinámica", "aculturación" y "cambio cultural". Esto es, se servía de argumentos que invocaban simultánea o alternativamente una secuenciación de etapas acumulativas o progresivas del desarrollo cultural (donde la adaptación y el control sobre el medio son factores decisivos) junto con otras que operaban de acuerdo a la influencia producida por el intercambio material, simbólico, las conquistas y guerras entre diferentes culturas ${ }^{36}$. Es por ello que no resulta extraño que haya sostenido años después que sólo un

organización de contextos sino de culturas a través de los distintos estilos. Yo me di cuenta que hacía falta eliminar la idea de que todo lo que se encontraba en el noroeste era diaguita porque, evidentemente, había una secuencia que era necesario establecer" (Bianciotti 2005:172)

36 Por ejemplo, la explicación sobre la génesis y desarrollo de la "cultura La Aguada" del área del noroeste argentino es una elocuente explicación de este tipo: "En un momento de la investigación arqueológica argentina existió la tendencia a atribuir una determinada cultura e influencias directas más o menos masivas de otras alejadas o no en el espacio [González y Pérez no lo dice aquí, pero serían las diversas perspectivas histórico culturales] Mientras más ahondamos en el estudio de estos temas se comprende que las culturas, si bien tienen características que le unen al resto de las del área, poseen rasgos propios. Estos son la resultante de influencias múltiples, de raíces que se hunden en el pasado y de adaptaciones y cambios frente al ambiente en el cual se las encuentra. Este aspecto esencialmente dinámico nos brinda una perspectiva más amplia. En el caso de La Aguada, sus orígenes, en parte, se pueden rastrear en las culturas que la precedieron: tiene elementos de Ciénaga y una buena cantidad de rasgos Condorhuasi. Estos elementos preexistentes recibieron el impacto cultural venido de otro lado; en términos generales, algunas ideas y aspectos tecnológicos parecen estar emparentados en forma directa con el gran desarrollo del período Tiahuanaco Clásico. Estas influencias no vinieron en forma directa desde las costas del Titicaca hasta el noroeste argentino. Es probable que hayan tenido una etapa de transformación en los oasis de la Puna chilena; desde aquí debieron filtrarse algunos elementos culturales hasta llegar al noroeste, implantándose sobre las culturas preexistentes. En nuestro territorio se modificaron algunos aspectos formales. Sin embargo, estos principios básicos llegados desde el norte son aún reconocibles: el personaje de los dos cetros, el sacrificador, el personaje con máscara felínica y el culto de los cráneos trofeos, fueron elementos que difícilmente pudieron ser reinventados. Llegaron como una constelación o complejo de ideas religiosas, formalmente estabilizadas en su arte, que se transformaron y adaptaron a las condiciones locales y a las técnicas existentes [...] Los elementos no debieron llegar simultáneamente, sino que se integraron en forma progresiva: es probable que en los comienzos arribaran algunos adelantos técnicos en la metalurgia y en la alfarería, diversos motivos decorativos como la llama feminizada y figuras antropomorfas; posteriormente, y en forma más integrada, otros elementos y especialmente la constelación felínica ya estabilizada. Probablemente esto obedece a la propia dinámica de los centros difusores. Luego de alcanzar la total integración, la estabilidad y su máximo desarrollo, poco a poco van perdiendo sus formas originales; los elementos componentes carecen de cohesión, son utilizados en forma aislada y los diseños naturales sufren una progresiva geometrización hasta llegar a ser abstractos y totalmente irreconocibles [...] Es interesante destacar que este mismo hecho ocurrió en la costa del Perú y en otros sitios cuando la cultura del Tiahuanaco-Wari dejó de ejercer su influencia sobre esos lugares" (González y Pérez 1972:73-74). 
análisis superficial del evolucionismo de Gordon Childe lo definiría como: "contracara de la kulturkreise. Pero si investigamos un poco más a fondo podemos demostrar que el kulturkreise tiene mucho de proceso evolutivo; por ejemplo, los círculos de cultura, los kreise, se superponen unos a otros en el espacio y en el tiempo, lo que es una manera particular de un proceso evolutivo, esto es muy claro" (Bianciotti 2005:177) 37.

Veamos ahora el programa de "Técnica de la investigación arqueológica" de Cigliano entre 1966 y 1976. Los contenidos, métodos y técnicas inicialmente incorporados de 1966 a 1969 prácticamente no variaron en los años subsiguientes, aun cuando se adicionaron algunos nuevos (que referiremos abajo). Los temas permanentes fueron: 1) La antropología como ciencia, sus divisiones y ciencias auxiliares (con especial referencia la historia). 2) La Arqueología y sus divisiones. 3) El desarrollo de los métodos y técnicas de investigación arqueológica correspondientes a la prehistoria, antigüedad, edad media, siglos XVIII, XIX y XX. 4) Clasificación de las fuentes antropológicas en diferentes tipos. 5) Ejemplos de estudios críticos de interpretación arqueológica. En relación con los métodos se destacan: 1) El trabajo de campo y sus etapas: preparación, prospección y recolección, relaciones con dimensiones de análisis geológico, topográfico, biológico, climático e hidrográfico. 2) Estratigrafía: distintos métodos y técnicas de excavación. 3) Trabajo en cavernas. 4) Arte rupestre: descripción y autenticidad, técnicas de relevamiento, motivos, estilos, cronologías. 5) Trabajo en tumbas o enterramientos. 6) Aplicación de la topografía y la fotografía aérea en arqueología. 7) Interpretación de los hallazgos: paleoecología, paleografía, cálculos de población, métodos de excavación, análisis de las viviendas, usos y costumbres. 8) Sedimentología. 9) Palinología. 10) Trabajo de gabinete: análisis tipológico y cronológico. 11) Métodos cronológicos de la arqueología: estratigrafía, dendrocronología, análisis de los estratos, turberas, playas antiguas. 12) Cronología relativa y absoluta: carbono 14, fluorina y otros. 13) Diario, inventario, protocolo, ficheros y catastros arqueológicos. 14) Publicación: congresos y revistas. En tanto que el análisis de las técnicas arqueológicas eran tratadas en las clases de trabajos prácticos, que referían a: 1)

\footnotetext{
37 Sopesando innovaciones y continuidades en los aportes teóricos y metodológicos provistos por González en la época, Javier Nastri destaca el marco neo-evolucionista que atribuye un papel fundamental en la explicación cultural al determinismo tecnológico. Para González los sistemas simbólicos objetivados en el parentesco, la religión, la lengua y el arte tendrían un carácter histórico único, azaroso y no acumulativo, en tanto que los objetos prácticos y la tecnología expresarían una lógica repetitiva, necesaria y de desarrollo acumulativo. Ahora bien, Nastri sostiene que González, a diferencia de Vere Gordon Childe, le imponía un límite a la eficacia social y explicativa del determinismo tecnológico en la constatación empírica, contradiciendo de este modo cualquier tendencia en el sentido de un progreso cultural unilateralmente diseccionado. Así pues: "La secuencia particular del noroeste argentino evidencia para González un 'retroceso' con la desintegración de la cultura La Aguada, cuya excelencia artística y técnica no habría sido superada por las posteriores culturas aborígenes" (2004:221).
}

Tipología de material lítico y cerámico. 2) Seriación cerámica. 3) Confección de croquis y lectura de mapas. 4) Observación del perfil del suelo. 5) Conservación de material antropológico. 6) Método estadístico. 7) Fichaje bibliográfico.

La bibliografía (con la excepción de Introducción al estudio de la prehistoria de Martín Almagro) eran abrumadoramente textos y autores anglosajones y franceses. En 1969 Cigliano acrecentó la bibliografía sumando autores expresivos de diferentes corrientes antropológicas metropolitanas. Los textos de la arqueología francesa referidos a prehistoria de Europa comprendían trabajos de: A. Leroi-Gourhan, Les fouilles prehistoriques y Les hommes de la préhistoire; F. Bordes, L'Anthropologie; D. Sonneville-Bordes, L'age de la Pierre; A. Laming, La découverte du passé; A. Laming-Emperaire, $L a$ arqueología prehistórica. Así como referencias a textos de Boule et Vallois, Les hommes de la pierre anciene; $\mathrm{P}$. Grand, La découverte de la préhistoire; R. Noguier, La géographie humaine préhistorique; A. Maury, L'Homme préhistorique. Por su parte, la bibliografía anglosajona sobre prehistoria y arqueología incluía: O.G.S. Crawford, Archaeology in the field; R.J. Braidwood, Archaeology; G.E. Daniel, The hundred years of archaeology; M. Wheeler, Archaeology from the earth; A.J. Goodwin, Method in Prehistory. G. Clark, Archaeology and Society, G.E. Daniel, The hundred years of archaeology, R.J. Atkinson, Field Archaeology. J. Kenyon, Achaeology in the holy land; G.F. Ekholm, New World culture history; V.A. Gorodzov, The tipological method in archaeology; W.E. Haury, Archaeological theories and interpretation. Sobre la arqueología prehistórica e indígena americana se incorporaban trabajos de: R.H. Lowie, American culture history; P. Martin et al, Indians before Columbus; P. Phillips et al, Method and theory in American archaeology; R. Redfield, The primitive World and its transformations; J. Olive Negrete, Estructura y dinámica en Mesoamérica.

Los trabajos específicos referidos a métodos y técnicas de relevamiento y de datación arqueológica eran: $F$. E. Zeuner, Dating the past y The Pleistocene period; R F. Flint, Glacial and Pleistocene Geology; O.G. Crawford, Air photography for archaeologists. I.G.N. Note sur le examen stéréoscopique des photographies aériennes. N. Horlaville, L'emploi des stéréogrammes dans la recherche archeologique, P. Chombart de Lauwe, Photogtraphies aériennes. L. Cagniard, La prospection géophysique F.E. Zeuner, Dating the past y The Pleistocene period. A.E. Douglas, Climatic Cycles and three growth. Por último, como bibliografía metodológica de referencia general para ciencias sociales se citaba F. Kaufmann, Metodología de las ciencias sociales; y sobre antropología física y arqueología: M.J.Aitken, Physics and archaeology.

Desde 1969 hasta 1973 no hubo modificaciones en la bibliografía, pero en este último año el ingreso de Rodolfo Raffino como jefe de trabajos prácticos redundó 
en la incorporación decisiva de textos de Cigliano, John Murra,y del propio Raffino, todos estrechamente asociados al tema de su tesis de doctorado. El curso de trabajos prácticos se cerraba en los primeros años con la elaboración de una monografía, o con un trabajo en equipo o un trabajo relacionado con el viaje de estudios de la cátedra. En el curso de 1969 se agregaron contenidos: la influencia del hombre sobre el paisaje, investigaciones sobre el terreno, geología del cuaternario, glaciaciones y sus relaciones con los vestigios prehistóricos, testigos, estructuras horizontales y verticales. Se enfatizaron métodos como la identificación de sitios históricos por observación directa, la investigación sistemática y la detección por propagación de ondas, la datación por fosfatos, la datación de cerámicas, el análisis tecnológico en útiles líticos y técnica de los metales, la preservación de monumentos y pinturas. El curso de trabajos prácticos de ese año estuvo centrado en métodos de fichaje bibliográfico, tipología de material lítico y de alfarería, técnica de relevamiento de arte rupestre, geocronología y aplicación del método estadístico (Francois Bordes y William Ford). Este año cabe destacar las referencias a Bordes y Leroi-Gourhan para el análisis tipológico de material lítico, así como la metodología de Antonio Serrano para tipologías cerámicas argentinas y las de Anne Sheppard. En el caso del estudio práctico del material lítico, se analizaron técnicas de talla de Patagonia, Noroeste Argentino, provincia de Buenos Aires y países limítrofes; y el cerámico referido a técnicas del Noroeste, Litoral y Buenos Aires.

En 1970 la bibliografía se diferenciaba entre básica y especializada, sin que ello supusiera importantes incrementos o supresiones en los textos de referencia. En 1973 se eliminó esa distinción ${ }^{38}$. En 1971 se incorporó el concepto de ecología humana como factor determinante en el análisis de un sitio arqueológico (junto con otros factores previamente referidos como los climáticos, geológicos, zoológicos, botánicos, humanos e históricos). Los métodos y técnicas de excavación fueron clasificados en forma desagregada según enterratorios, unidades habitacionales o basurales. Se incorporó también el método de termoluminicencia y a los estudios técnicotipológicos (además del lítico, cerámico y metales que ya eran considerados) se sumó la madera y materiales óseos. En el curso de trabajos prácticos se enfocaron: a) la investigación en cuevas, unidades habitacionales,

\footnotetext{
38 H. Alimen, Atlas de Préhistoire; F. Bergounioux y A. Glory, Les premmiers hommes. I. Bernal, Introducción a la arqueología. H. Breuil, La Préhistoire, Prolégoménes a une classification préhistorique y L'homme de la pierre ancien. D.A. Garrod, Eviroments, tools and man. F. Hole y Heizer, An introduction to prehistorie archaeology. A. Laming-Emperaire, La décuverte du passé. Y entre la bibliografía clasificada como especial, los nuevos fueron: C.M. Lerici, Propezioni archeogiche. J. Belshe, Archaeomagnetism. W. Broeker, The radiocarbon method of age determination. M. Campo, Derniers résultats de l'analyse pollinique des tourbes en France. W. Lobby, Radiocarbon dating. G. Erdtman, An introduction to pollen analysis. K.P. Oakley, Flourine and the relative dating of bones y The flourine. Dating method.
}

basurales y tumbas; b) las técnicas de relevamiento de arte rupestre, pictografía y petroglifos; estratigrafías de diferentes tipos; tipologías de materia lítico del Viejo Mundo y América; c) tipología y técnicas de elaboración de material cerámico; d) la seriación y el tratamiento de muestras según los métodos de los métodos de Bordes y Ford (que ya eran trabajados) y el de Meggers; e) y la aplicación del método estadístico a una muestra del Noroeste Argentino. Ese año se incluyeron como textos en la bibliografía especializada: E. Evans Pritchard, Social Anthropology, past and present; Gómez Tabernera, Introducción al estudio de la etnología; J. Ford, Método para establecer cronologías culturales; B. Meggers y C. Evans, Cómo interpretar el lenguaje de los tiestos; F. Bordes, Tipología del Paleolítico Superior; y A. Serrano, Normas para la clasificación de la cerámica arqueológica. ${ }^{39}$

En 1973 el concepto de ecología humana adquirió mayor significación constituyendo una unidad temática específica y desagregándose en los conceptos subsidiarios de área ecológica, área cultural y modelos culturales. Recordemos que ese año Raffino -recién doctorado con dirección de Cigliano- ingresaba como jefe de trabajos prácticos. Este concepto estaba asociado a sus preocupaciones teóricas y sustantivas de investigación. Los nuevos textos eran solidarios con esas innovaciones: J. Ford, A comparation of formative cultures in the Americas; E, Lanning, Perú before the Incas; J. Murra, El control vertical de un máximo de pisos ecológicos en la economía de las sociedades andinas; P. Kosok, Life, land water in ancient Perú; Ch. Usca Goitía, Breve historia del urbanismo; y A. Korn, La historia construye la ciudad. En tanto que se incluyeron por primera vez trabajos de arqueólogos de la FCNyM: Cigliano, El Ampajanguense; Tastil una ciudad preincaica argentina; de Cigliano y Raffino, Tastil, un modelo cultura de adaptación, funcionamiento y desarrollo de una ciudad urbana prehistórica; de Raffino, Las sociedades agrícolas del período tardío en la Quebrada del Toro y aledaños y Agricultura hidráulica y simbiosis económica y demográfica en la Quebrada del Toro, Salta, Argentina; de Raffino y Cigliano, La Alumbrera-Antofagasta de la Sierra: un modelo de ecología cultural prehispánica; de Cigliano, Raffino y Horacio Calandra, Nuevos aportes para el conocimiento de las entidades alfareras más tempranas del Noroeste Argentino; de Cigliano, Raffino y María Amanda Caggiano, Resultados de las investigaciones realizadas en Salto Grande; de González, Cultural Development in Northwestern Argentina; de González y José Pérez, El área andina meridional; y Néstor H. Palma, Transfiguraciones antropológicas de la Puna Argentina ${ }^{40}$.

El curso de trabajos prácticos de 1973 también planteó innovaciones proponiendo una secuencia de etapas en

\footnotetext{
39 Al año siguiente se incluiría de F. Bordes, Tipología del paleolítico antiguo y medio y El hombre del mundo cuaternario.

40 Palma integraba el grupo académico de Vivante.
} 
una "investigación arqueológica ideal": a) preeliminares, hipótesis; b) trabajo de campo; c) trabajo de laboratorio. $1^{\circ}$. Análisis de fuentes: fichaje y bibliografía. $2^{\circ}$. Prospección arqueológica: a) delimitación del área de estudio; b) excavación diagnóstica; c) excavación sistemática. $3^{\circ}$. Selección de indicadores: tipología cerámica, tipología lítica, tipología de otros indicadores. Para la seriación cerámica: métodos de Ford y de Evans. Para la seriación lítica: métodos de Anette Laming-Emperaire, Bordes, Bagolini. $4^{\circ}$. Correlaciones. $5^{\circ}$. Cronología. Formulación de conclusiones y demostración de hipótesis. Y en 1974 la unidad temática referida a ecología humana sumó el concepto de ecosistema. Sobre el final del programa de este año fueron colocadas dos unidades completamente novedosas. Una sobre los conceptos de contexto cultural, cultura desde el punto de vista arqueológico y clasificaciones culturales temporales y espaciales. La otra unidad planteaba la necesidad de relacionar temas de la agenda política y estatal argentina de la época con la agenda de los estudios arqueológicos, considerando la "aplicación de las investigaciones arqueológicas al quehacer nacional y sus alcances en lo cultural, en lo económico y en lo social para la reactivación e integración de zonas".

Ese año el curso de trabajos prácticos mantuvo la propuesta de seguir la secuencia de etapas de una "investigación arqueológica ideal". La bibliografía de 1974 y 1975 fue significativamente reducida a los citados textos de Alimen, G. Clark, Ford, Laming, Kaufmann, Zeuner, Olivé Negrete, Cagniard, Bordes, Haury, Lowie, Bagolini, Murra, Nogier y Korn. Fueron incorporados dos nuevos en 1975: Jorge Hardoy, La urbanización en América Latina (de influencia en la conceptualización histórica de lo urbano empleada por Cigliano en su análisis de Tastil) y de Gordon Willey Prehistoric settlement patterns in the Virú Valley. De los arqueólogos de la FCNyM sólo se mantuvieron textos de Cigliano, Raffino y Palma. Finalmente, en el programa de 1975 y 1976 fueron suprimidas las dos unidades adicionadas el año anterior y se conservó la propuesta de trabajos prácticos. Así pues, el clima político represivo que se vivió con la intervención universitaria del gobierno nacional de Isabel Perón y luego con el golpe militar del 24 de marzo de 1976 dejaron huellas (por censura o autocensura) limitando los enunciados programáticos, contenidos, autores y bibliografía del programa de la materia ${ }^{41}$.

\section{Reflexiones finales}

Desde la muerte de Márquez Miranda, los antropólogos Alberto Rex González y Eduardo Mario Cigliano compitieron por el control de los recursos materiales, financieros y humanos destinados a la producción científica en arqueología. Sus trayectorias en la FCNyM se discontinuaron casi simultáneamente. González fue

\footnotetext{
41 Recordemos que tras fallecer Cigliano en 1977, la materia fue dictada por Augusto Cardich.
}

exonerado en 1976 y Cigliano falleció al año siguiente a los cincuenta y un años. Pero discípulos platenses formados con uno -Bernardo Dougherty y María Carlota Sempé de Gómez Llanes- y otro -Rodolfo Raffinocontinuaron investigando en las Divisiones del Museo y enseñando en las cátedras de la Facultad. Aquí hemos pretendido dar cuenta de los temas, autores y textos, enfoques y métodos enseñados en las dos cátedras de la Licenciatura que estuvieron a su cargo durante más tiempo: "Arqueología Argentina" y "Técnica de la Investigación Arqueológica".

En relación con González, señalamos que su programa ofrecía un recorrido histórico y regional sirviéndose de trabajos de arqueólogos argentinos y extranjeros. Ese recorrido intelectual definía un corpus teórico heterodoxo de textos y autores canónicos que González, sin dudas, contribuyó a instalar como referencias indispensables en la enseñanza de la arqueología argentina. Dicho corpus, sin embargo, no era igualmente comprehensivo y exhaustivo de todas las áreas culturales definidas en el programa, ya que el énfasis estaba colocado en autores, textos y tópicos específicos correspondientes al área del Noroeste Argentino y regiones vecinas, pues era en ésta donde González y sus discípulos concentraban sus principales esfuerzos de investigación. De allí que, además, la enseñanza de la arqueología de este área cultural estuviese estrechamente ligada a concepciones teóricas e investigaciones empíricas de "peruanistas" norteamericanos como Wendell Bennett y Gordon Willey.

Hemos visto que González combinaba explicaciones sobre el desarrollo y el cambio cultural que implicaban alternativa o simultáneamente -según los contextos- el recurso a visiones evolucionistas o difusionistas, asociadas al uso de conceptos como adaptación humana al medio ecológico, desenvolvimiento tecnológico como instrumento de control del hombre sobre ese medio y, además, enfocando los intercambios simbólicos y materiales producidos entre grupos sociales ${ }^{42}$. Un dato que puede llamar la atención al lector es que las recurrentes referencias programáticas y en testimonios de González acerca de la influencia operada en él por enfoques ecológico-culturales y el neo-evolucionismo (particularmente Steward y Childe) no se objetivaron en reconocimientos explícitos en el programa de la materia ${ }^{43}$. A su vez, si bien en los últimos

\footnotetext{
42 Como observa Gastón Gil (2010) tampoco a Steward se le escapaba la posibilidad analítica de combinar evolución y difusión en sus explicaciones, pero siempre y cuando esta última diera cuenta sólo de aspectos secundarios de la cultura. Como sostiene Gil, para Steward el núcleo cultural era resultado de una dinámica evolutiva multilinear de interrelación funcional entre patrones de subsistencia y asentamiento, estructura social, trabajo cooperativo, guerra y religión.

43 pólogos que publicaron en el Handbook of South American Indians. El Handbook editado por Julian Steward también fue una referencia cuando González dictó entre 1966 y 1968 la materia "Arqueología Americana (Culturas Agroalfareras)", donde junto con trabajos de Wendell Bennett, Gordon Willey, José Alcina Franch, Wilhelm Schmidt, Paul Kirchohff, Pedro Armillas, J. H. Rowe y otros, era empleado en el
} 
programas de "Arqueología Argentina" incorporó una mención a la "nueva arqueología", no tenemos certeza de que los enfoques y métodos de esta corriente de la arqueología anglosajona fuesen enseñados en sus cursos, pues no existen referencias a autores y textos expresivos de la misma (los textos de Lewis Binford de la década de 1960 y la propia polémica entre Bordes y Binford están ausentes en los programas de González y de Cigliano) ${ }^{44}$. Por último, la materia no era de formación metodológica, pero la enseñanza de métodos y técnicas de datación eran colocadas en primer plano, ya que las consideraba un recurso para cuestionar interpretaciones especulativas como las de Márquez Miranda y otros histórico-culturales.

Por su parte, los contenidos, autores y textos incorporados por Cigliano evidencian que sus concepciones acerca de la arqueología no expresaban una lisa y llana continuidad respecto de los enfoques históricos culturales y métodos asistemáticos de trabajo en terreno enseñados y practicados por Márquez Miranda, de quien -recordémoslo- se reconocía discípulo. En ese sentido, Myriam Tarragó (2003) -que investigó con Cigliano durante su paso por la Universidad Nacional del Litoral- ha considerado los trabajos de investigación de Cigliano de fines de los años cincuenta y principios de los sesenta como parte de un movimiento que dejaba de pensar el sitio en forma aislada $y$, por el contrario, comenzaba explorar la noción relacional y contextual de "área cultural"45. Además Cigliano innovaba respecto de su maestro apelando a la enseñanza de la estratigrafía y el fechado por carbono 14 como métodos de datación e indagando en tipologías e industrias líticas de arqueólogos franceses (Bordes, Leroi-Gourhan y Laming) y cerámicas de norteamericanos (Meggers, Evans y Sheppard) ${ }^{46}$. En

tratamiento de las unidades temáticas sobre las denominadas "grandes teorías de síntesis" sobre las "culturas americanas", con especial énfasis en el área de Mesoamérica y la Andina (incluyendo el Noroeste Argentino).

44 Susana Luco (2010) recuerda que González hizo referencia en el Primer Congreso Nacional de Arqueología (1970) a la "new archaeology" pero no a Binford; destaca, a su vez, que en los cursos de "Prehistoria y Arqueología Americana I", Ciro René Lafón introdujo la polémica Bordes-Binford. Luco también menciona que dos discípulos de González -Myriam Tarragó y Víctor Núñez Regueiro- en la década de 1970 incluían a Binford en la bibliografía de sus materias, aún cuando como dice un informante- no los aplicaron o no los usaron en sus investigaciones. Por último, de acuerdo con un graduado platense que cursó con Raffino en los años setenta, éste refería a otro exponente de la "nueva arqueología", David Clarke, en sus clases, a pesar que no existen citas a textos de este arqueólogo en el programa de trabajos prácticos "Técnica de la investigación arqueológica".

45 Cabe destacar además que, así como González llevó a cabo un movimiento de aproximación entre la arqueología y la antropología social en su equipo a partir de las investigaciones desarrolladas en Laguna Blanca, Cigliano planteó una interlocución similar en su proyecto en el Valle de Santa María. Para una exposición de resultados parciales de una y otra experiencia fueron expuestos en Cruz (1968) y Meister, Petruzzi y Sonzogni (1963). En ambos casos estaba la impronta teórica de los antropólogos norteamericanos Julian Steward y Robert Redfield.

${ }^{46}$ Ciertamente al decir esto no puede omitirse el hecho que Márquez Miranda y Ciro René Lafón incluyeran en el programa de "Prehistoria y relación con esta última afirmación, puede decirse que la apropiación de enfoques y métodos de las arqueologías metropolitanas contemporáneas emprendida por Cigliano en la enseñanza de "Técnicas de la investigación arqueológica" era comparativamente más extensa y diversa que la ofrecida por Oswald Menghin en el curso de "Técnica de la investigación (ciencias antropológicas)" que dictaba en la Facultad de Filosofía y Letras de la UBA ${ }^{47}$. Sin embargo, no se trataba de un hecho aislado en la época. Susana Luco (2010) sostiene que el responsable de la introducción de la tipología lítica de Bordes en la Argentina fue Marcelo Bórmida; en tanto que Carlos Aschero habría introducido a Leroi-Gourhan entre los arqueólogos locales. En este sentido, la circulación de conocimientos y usos prácticos de los arqueólogos franceses tuvo un campo fértil en la Patagonia ${ }^{48}$.

Por último, hemos observado que la incorporación de Raffino a la cátedra de Cigliano en 1973 implicó cambios en la enseñanza de la materia, los cuales redundaron en una mayor presencia de enfoques que recurrían a conceptos de la antropología norteamericana como área ecológica, área cultural y modelos culturales. Estas modificaciones abrieron un espacio de interlocución más estrecha con el abordaje de autores y textos del programa de "Arqueología Argentina" de González, particularmente con aquellos relativos a la arqueología del Noroeste Argentino y regiones vecinas y, en consecuencia, al diálogo con las influencias de la antropología neoevolucionista y de la ecología cultural norteamericana ${ }^{49}$.

Arqueología" dictado en la Facultad de Filosofía y Letras de la UBA en 1961 trabajos de Meggers y Evans sobre arqueología del Ecuador y el texto de Bennett del Handbook of South American Indians.

47 Menghin incluía en su programa de 1963 los siguientes textos: Bernal, Introducción a la arqueología; Crawford, Archaeology in the field; Du Mesnil du Boison, La technique de fouilles archéologiques; Goodwin, Method in Prehistory; Heitzer, A guide for archaeological field methods; Laming, La découverte du passé; Leroi-Gourhan, Les foullies préhistoriques. Techniqués et méthodes; Pescheck, Lehrbuch der Urgeschichteforschung; Romero, Técnica antropológica de exploración; Vayson de Pradenne, Les fraudes en archéologie préhistorique; Wheeler, Archaeology from the Earth.

48 Aún así hay que destacar que de esta iniciativa renovadora en la enseñanza de la arqueología francesa -como fue señalado por Gustavo Politis (1992) y Myriam Tarragó (2003)- tuvo también en González un difusor con la concreción del curso de análisis de materiales de JeanClaude Gardin, investigador del Centre d'Analyse Documentaire pour I'Archéologie del CNR.

49 Los conceptos de "cultura", "contexto cultural", "desarrollo cultural", "difusión", reconocibles en los programas y en buena parte de la literatura especializada arriba mencionada, en la época no gozaban de un consenso pleno entre aquellos arqueólogos que promovían enfoques renovados y críticos de los histórico-culturales. Así, Víctor Núñez Regueiro, discípulo de González, publicaba en un artículo crítico en el que no sólo proponía una revisión de esas categorías teóricas de impronta antropológica norteamericana aplicadas al estudio del noroeste argentino, además, abogaba por la elaboración de un marco teórico marxista que se sirva del "análisis del modo de producción de las entidades socio-culturales prehispánicas e hispano-indígenas, y evaluando críticamente el concepto de 'difusión', que por lo general se lo ha utilizado en forma desmedida para intentar explicar o describir los procesos culturales que han tenido lugar" (1974:169). 
Ahora bien, antes de finalizar el artículo destaquemos algunos interrogantes pendientes que deberemos responder en instancias subsiguientes de esta investigación.

En primer lugar, González y Cigliano dictaron en la década de 1960 otras cátedras como "Prehistoria General", "Prehistoria del Viejo Mundo", "Arqueología Americana (culturas pre-ceramicas)" y "Arqueología Americana (culturas agro-alfareras)": en qué medida los temas, enfoques y métodos, autores y bibliografía comprendidas por ellos fueron continuados, modificados o relegados por quienes los sucedieron, Pedro Krapovickas, Antonio Austral, Ana María Lorandi y Augusto Cardich. La respuesta a esta pregunta requerirá explorar en la formación y producción académica, trayectoria institucional y relaciones personalizadas de estos últimos ${ }^{50}$.

En segundo lugar, será necesario identificar y profundizar en el conocimiento de los vínculos existentes entre la enseñanza en las cátedras e las investigaciones en las Divisiones o en proyectos dirigidos por González y Cigliano, sirviéndonos para ello de una revisión de informes, publicación de artículos y libros de estos líderes académicos y miembros de sus grupos, presentaciones a congresos y dirección y elaboración de tesis de doctorado, observando en cada caso si existen correspondencias y/o discontinuidades con lo enseñado en las cátedras ${ }^{51}$.

En tercer lugar, dado que la inscripción y circulación de González y Cigliano se proyectaban en forma significativa hacia otras localizaciones institucionales (particularmente Rosario y Córdoba), es imprescindible dar cuenta de ellas, aunque más no fuese para comprender mejor qué eficacia social ejercían en sus actividades en el ámbito platense. En este sentido, valdría la pena indagar en las representaciones pasadas y presentes construidas por los llamados o autodenominados "arqueólogos platenses" o por la "arqueología platense" sobre quiénes eran y quiénes son comprendidos en términos nativos como actores sociales expresivos de esa identidad científica e institucional local y, contrariamente, quiénes eran o son rotulados como sujetos foráneos, ajenos o dudosamente autóctonos.

Restaría, por último, abordar una dimensión clave para el análisis de la configuración de liderazgos y grupos académicos, cual es el estudio de las relaciones personalizadas establecidas por estos dos antropólogos con sus colegas, discípulos y estudiantes de la FCNyM/

\footnotetext{
50 En especial, merecería ser explorada la trayectoria de Augusto Cardich, teniendo en cuenta que su presencia intelectual e institucional ha sido duradera en la FCNyM -proyectándose prácticamente hasta a el presente- como profesor, investigador y director de tesistas de doctorado. Asimismo, la impronta de Cardich también se destaca por la influencia alcanzada por sus trabajos sobre otros colegas, tal como puede reconocerse en el estudio de citas bibliográficas en artículos de revistas especializadas efectuados por Bonnín y Laguens (1984-1985) para la década de 1960 y comienzos de los ochenta.

51 Para el caso de González: Bonnín y Soprano 2010.
}

UNLP. A tal efecto, será preciso realizar entrevistas a protagonistas que testimonien sobre esas relaciones y, en particular, sobre la enseñanza en las cátedras de arqueología y sus vínculos con las tareas en laboratorios y viajes de campaña.

Bernal, 25 de agosto de 2010

\section{Agradecimientos.}

Agradezco los comentarios críticos formulados a versiones de este artículo por Rosana Guber, Gastón Gil y Gustavo Politis, así como a los colegas del PICT/R 1728 por sus sugerencias y al personal de la Biblioteca Florentino Ameghino de la Facultad de Ciencias Naturales y Museo por su profesional y cálida atención.

\section{Bibliografía}

Bianciotti, A. 2005. "Alberto Rex González: la imagen y el espejo". Arqueología Sudamericana vol. 1 N²: 155-211.

Bonnín, M. y A. Laguens. 1984-1985. "Acerca de la arqueología argentina de los últimos 20 años a través de las citas bibliográficas en las revistas Relaciones y Anales de Arqueología y Etnología". Relaciones de la Sociedad Argentina de Antropología XVI: 7-25.

Bonnín, M y G. Soprano. 2010. "Antropólogos y antropología entre las universidades nacionales de La Plata, Litoral y Córdoba. Circulación de personas, saberes y prácticas antropológicas en torno del liderazgo académico de Alberto Rex González (1949-1976)". Ponencia II Jornadas de Historia de la Universidad Argentina, Universidad Nacional de General Sarmiento, Los Polvorines.

Cigliano, E. M. 1960. Investigaciones arqueológicas en el Valle de Santa María. Publicación $N^{\circ} 4$, Instituto de Antropología, Universidad Nacional del Litoral, Rosario.

Cigliano, E. M. 1962. El Ampajanguense. Publicación N5, Instituto de Antropología, Facultad de Filosofía y Letras, Universidad Nacional del Litoral. Rosario.

Cruz, J. 1968. "Vida y aislamiento. Un enfoque antropológico del ciclo vital en Laguna Blanca, Catamarca". Revista del Museo de La Plata (Nueva Serie), Tomo VI, Antropología N³5: 239-279.

Farro, M. 2009. La formación del Museo de La Plata. Coleccionistas, comerciantes, estudiosos y naturalistas viajeros a fines del siglo XIX, Prehistoria Ediciones, Rosario.

Farro, M; I. Podgorny y M. Tobías. 1999. “Notas para un ensayo de la recepción de la 'Nueva Arqueología' en la Argentina". Revista del Museo de Arqueología y Etnología 3: 221-234. 
García, S. 2003. El Museo de La Plata y la divulgación científica en el marco de la extensión universitaria (1906-1930), Tesis Doctor Facultad de Ciencias Naturales y Museo / UNLP.

Gil, G. 2010. Neoevolucionismo y ecología cultural. La obra de Julian Steward y la renovación de la enseñanza de la antropología en la Argentina. Revista del Museo de Antropologia 3: 225-238.

González, A. R. 1959. "Observaciones al trabajo de F. M. Miranda y E. M. Cigliano. 'Ensayo de una clasificación tipológico-cronológica de la cerámica santamariana". Revista del Instituto de Antropología I: 315-330.

González, A. R. 2000. Tiestos dispersos. Voluntad y azar en la vida de un arqueólogo. Emecé, Buenos Aires.

González, A. R. y J. A. Pérez. 1972. Argentina indígena, víspera de la conquista. Paidós, Buenos Aires.

Guber, R. 2006. "Linajes ocultos en los orígenes de la antropología social de Buenos Aires". Avá, Revista de Antropología No 8: 26-55.

Luco, S. 2010. De prehistoriadores a arqueólogos. Una etnografía del cambio de paradigma en la práctica académica de la arqueología antagónica. UBA (19751983), Tesis de Maestría Antropología Social, IDES/IDAESUNSAM, Buenos Aires.

Meister, Albert; S. Petruzzi y E. Sonzogni. 1963. Tradicionalismo y cambio social, Publicación N¹, Instituto de Antropología, Universidad Nacional del Litoral, Rosario.

Nastri, J. 2003. "La arqueología argentina y la primacía del objeto". G. Politis y R. Peretti (eds.), Teoría Arqueológica en América del Sur, 213-321, Universidad Nacional de Centro de la Provincia de Buenos Aires, Olavaria.

Núñez Regueiro, V. 1974. "Conceptos instrumentales y marco teórico en relación al análisis del desarrollo cultural del noroeste argentino". Revista del Instituto de Antropología V: 169-190.

Palavecino, E. 1948. Áreas y capas culturales en el territorio argentino. Imprenta Casa Coni, Buenos Aires.

Pérez Gollán, J. 1998. "Presencia de Alberto Rex González en la Universidad de Córdoba", Estudios No 10, 17-30, Centro de Estudios Avanzados, Universidad Nacional de Córdoba. Córdoba.

Podgorny, I. 1995. "De Razón a Facultad. Ideas acerca de las funciones del Museo de La Plata entre 1880 y 1920", Runa No22: 89-104.

Politis, G. 1992 (ed.) Arqueología Latinoamericana Hoy.
Biblioteca Banco Popular, Bogotá.

Politis, G. 1995. "The socio politics of the development of archaeology in Hispanic South America". P. Ucko (ed.), Theory in Archaeology. A World Perspectiva, 197-228, Routledge, Londres.

Politis, G. 2003. "The theoretical landscape and the methodological development of arcaheology in Latin America". American Antiquity 68 (2): 242-272.

Rodríguez, L. y A. M. Lorandi. 2005. “Apropiaciones y usos del pasado. Historia y patrimonio en el valle Calchaquí". Bulletin del'Institut Francais d'Études Andines 34 (3): 431-442.

Soprano, G. 2007. "Continuidad y cambio en los estudios en etnología de poblaciones indígenas contemporáneas y comunidades folk en la Facultad de Ciencias Naturales y Museo de la Universidad Nacional de La Plata (19301976)", Anuario de Estudios en Antropología Social 3: 23-52.

Soprano, G. 2009a. "Política, instituciones y trayectorias académicas en la universidad argentina. Antropólogos y antropología en la Universidad Nacional de La Plata entre las décadas de 1930 y 1960". M. Marquina, C. Mazzola y G. Soprano (comps.), Políticas, instituciones y protagonistas de la universidad argentina, 111-152, Buenos Aires, Universidad Nacional de General Sarmiento / Universidad Nacional de San Luis / Prometeo Libros.

Soprano, G. 2009b. "La antropología física entre la Universidad y el Estado. Análisis de un grupo académico universitario y sus relaciones con las políticas públicas del Instituto Étnico Nacional (1946-1955)", Estudios Sociales. Revista Universitaria Semestral N³7: 63-96.

Soprano, G. 2009c. "Autonomía universitaria e intervención política en la trayectoria de liderazgos y grupos académicos en ciencias naturales de la Universidad Nacional de La Plata. 1930-1955", Anuario del Instituto de Historia Argentina No 9 : 97-147.

Soprano, G. 2009d. "De la antropología física a la antropología biológica. Comunidades académicas y cambios políticos e institucionales en la formación e investigación antropológica de la Universidad Nacional de La Plata (décadas de 1960-1970)". VIII Reunión de Antropología del MERCOSUR, Universidad Nacional de San Martín, Buenos Aires.

Soprano, G. en prensa. "Clientelismo y facciones: del estudio de la política en el peronismo al conocimiento de las formas de sociabilidad universitaria. Potencialidades y limitaciones de conceptos clásicos". O. Aelo (coord.). Teorías y prácticas políticas en América Latina. Cambios y continuidades en el escenario regional, Editorial de la 
Universidad Nacional de Mar del Plata. Mar del Plata.

Tarragó, M. 2003. "La arqueología en los Valles Calchaquíes en perspectiva histórica", Anales del Museo de Gotemburgo: 13-42.

Visacovsky, S; R. Guber y E. Gurevich. 1997. "Modernidad y tradición en el orígen de la carrera de Ciencias
Antropológicas de la Universidad de Buenos Aires". Redes. Revista de Estudios Sociales de la Ciencia vol. 4 No10: 213-258.

Wolf, E. 1980. "Relaciones de parentesco, de amistad y de patronazgo en las sociedades complejas". M. Banton (comp), Antropología social de las sociedades complejas, 19-39, Alianza Editorial, Madrid. 